OPEN ACCESS

Edited by:

Milan Surjit,

Translational Health Science and Technology Institute (THSTI), India

Reviewed by:

Jawed labal,

Jamia Millia Islamia, India

Binod Kumar,

Loyola University Chicago,

United States

*Correspondence:

Nirupma Trehanpat

trehanpati@gmail.com

Specialty section:

This article was submitted to

Virus and Host,

a section of the journal

Frontiers in Cellular and Infection

Microbiology

Received: 12 March 2020

Accepted: 04 June 2020

Published: 11 August 2020

Citation:

Sehgal R, Bedi $O$ and Trehanpati N

(2020) Role of Microbiota in

Pathogenesis and Management of

Viral Hepatitis

Front. Cell. Infect. Microbiol. 10:341

doi: 10.3389/fcimb.2020.00341

\section{Role of Microbiota in Pathogenesis and Management of Viral Hepatitis}

\author{
Rashi Sehgal, Onkar Bedi and Nirupma Trehanpati* \\ Department of Molecular and Cellular Medicine, Institute of Liver and Biliary Sciences, New Delhi, India
}

Hepatitis is a condition that can be self-limiting or can progress to fibrosis (scarring), cirrhosis, or liver cancer. These days, gut microbiota becomes an important part of our immune system, which is important for disease progression or recovery. Translocation of gut microbial and metabolic products causes intestinal inflammation by modulating immune cells leading to impairment of the primary barrier. But there are limited studies discussing pathogenesis and management of hepatitis with gut microbiota. In this review, we have discussed the role of gut microbiota in pathogenesis and management of various hepatitis, especially hepatitis $\mathrm{B}$ and $\mathrm{C}$. We have discussed the role of bacterial products, LPS-TLR4 pathway, and unmethylated CpG DNA, which ultimately affects downstream NF-kB signaling in hepatitis. Finally, we have discussed the role of fecal microbiota transplantation in the management of hepatitis.

Keywords: hepatitis, fecal microbiota transplantation, gut microbiota, lipopolysaccharides (LPS), probiotic, bacteria

\section{INTRODUCTION}

Hepatitis is generally known as an inflammation of the liver that can be caused by hepatic and non-hepatic viruses, can be caused by alcohol, can be drug induced, and can be caused by autoimmunity. Gut microbiota composition is known to be associated with disease pathogenesis. However, dynamic alteration of the gut microbiota in disease pathogenesis is not well-understood.

Microbiota involves communities of commensal, symbiotic, as well as pathogenic microorganisms found in organisms, i.e., plants and animals. Microbiota of a healthy individual shows more of commensalism or symbiosis without causing any disease. These microbes mainly colonize humans during birth or shortly thereafter and remain throughout the course of life. These can be found in many areas like skin, respiratory tract, urinary tract, and digestive tract, while brain, lungs, and the circulatory system are free of microbes. Approximately $10^{14}$ microbes are present in a healthy individual gut (Minemura and Shimizu, 2015). Therefore, gut microbiota has an important role to modulate the immune system in disease progression or recovery.

Translocation of microbes or their metabolic products cause intestinal inflammation leading to impairment of the primary barrier (Hill et al., 2010). There is limited available information regarding the role of gut microbiota in hepatitis, which makes it important to majorly focus on clinical data of gut microbiota linked with hepatitis B and C virus.

\section{GUT MICROBIOTA}

Gut or gastrointestinal tract starts from the mouth and ends at the back passage (anus). Gut helps in the digestion of food by absorbing energy and nutrients. Majority of gut microbiota ( 80 to $85 \%$ ) contains good bacteria, and only 15 to $20 \%$ are harmful bacteria in different parts of the intestine 
(Bajaj et al., 2014). In mouth and upper respiratory tract, normal flora is more of the commensal bacteria like Streptococcus, Moraxella, Neisseria, and Haemophilus. Very few species of bacteria are present in the stomach and small intestine, while the large intestine and colon contain dense population of microbes, i.e., up to $10^{12}$ cells/g. Along with bacteria, many other microorganisms like fungi, protists, archaea, and viruses also symbiotically harbor in the gut.

There are four dominant phyla of bacteria present in the gut, and they are Firmicutes, Bacteroidetes, Actinobacteria, and Proteobacteria (Khanna and Tosh, 2014). Most important genera in which bacteria belong are Bacteroides, Clostridium, Faecalibacterium, Eubacterium, Ruminococcus, Peptococcus, Peptostreptococcus, and Bifidobacterium (Fernández et al., 2018). Some of the fungal species that also coexist in the gut are Candida, Saccharomyces, Aspergillus, Penicillium, Rhodotorula, Trametes, Pleospora, Sclerotinia, Bullera, and Galactomyces, among others (Raimondi et al., 2019).

\section{Functions of Gut Microbiota}

Gut microbiota plays an important but diverse role such as barrier effect, vitamin synthesis, and fermentation. Resident bacteria of the gut acts as a barrier and protect the intestinal mucosa from invasion of the other potential pathogens (Hooper et al., 1999). Many factors including diet, age, medication, illness, stress, and lifestyle influence the gut microbiota, which have a great impact on disease pathogenesis. In fact, many bacteria, i.e., Bacteroides, Eubacterium, Propionibacterium, and Fusobacterium, are instrumental in the synthesis of vitamins $\mathrm{K}$ and B (i.e., folate, B12, and biotin) (Canny and McCormick, 2008). They are also involved in the fermentation of nondigestible carbohydrates for the production of short-chain fatty acids (SCFAs), which are helpful in maintaining metabolic homeostasis. In addition to the production of SCFA, glycolysis and pentose phosphate pathway also produce butyrate, which promotes the growth of Lactobacilli and Bifidobacteria bacteria in the colon (Venegas et al., 2019). Various studies supported the fact that nutrients derived from microbiota play a pivotal role in the normal functioning of the hepatic system (Li et al., 2012; Zheng et al., 2013; Moratalla et al., 2014; Jiminez et al., 2016; Cremer et al., 2017; Wang et al., 2017a).

\section{Gut Microbiota in Liver Diseases}

Commensal bacteria play a decisive role in maintaining immune homeostasis (Figure 1) and also guard immune reactions at mucosal surfaces (Ichinohe et al., 2011). Intestinal microflora is a dynamic and complex ecosystem, which helps in proliferation, growth, and differentiation of epithelial cells to fight infections and improve immunity. Despite its crucial role in the synthesis of vitamin $\mathrm{K}$, folate, SCFA, and peroxides, gut microbiota acts as a chief environmental as well as etiological factor for the progression of many liver diseases (O'Hara and Shanahan, 2007). Particularly, gut microbiota has a larger influence on alcoholic liver disease, non-alcoholic fatty liver disease, viral hepatitis (hepatitis B and C), autoimmune hepatitis (AIH), primary sclerosing cholangitis (PSC), and primary biliary cholangitis (PBC) (Mohamadkhani, 2018).
Lactobacillus, Bifidobacterium, Saccharomyces boulardii, and Lactobacillus plantarum play a bigger role in the management of various metabolic disorders and hepatitis (Mohamadkhani, 2018).

Several pathogens, including viruses and intestinal microorganisms, use mucous membranes as a doorway (Karst, 2016). Hepatic viruses breach the intestinal permeability leading to gut dysbiosis and release pro-inflammatory cytokines instrumental in developing liver cirrhosis and HCC. It is also observed that the use of probiotics reduces the tolerogenic response and enhances the mucosal defense against viral pathogens (Rigo-Adrover M del et al., 2018). Lactobacillus alone can influence the production of interferon by modulating the antiviral effects of vitamin A (Lee and Ko, 2016). The mixture of various probiotics and Bifidobacterium with galactooligosaccharides and fructo-oligosaccharides has a defensive effect against Rotavirus infection by aggregating the production of TNF- $\alpha$, IL-4, IFN- $\gamma$, and TLR2 expression (Rigo-Adrover M del et al., 2018). In most of the liver disease, especially cirrhosis, dysbiosis of the gut increases Proteobacteria, Enterobacteriaceae, and Veillonellaceae, while it decreases Bacteroidetes and Lachnospiraceae (Sanduzzi Zamparelli et al., 2017). Recently, the cirrhosis dysbiosis ratio (CDR) is coined for defining the changes in gut microbiome in cirrhosis patients with beneficial Lachnospiraceae and Ruminococcaceae and harmful Enterobacteriaceae bacteria (Bajaj et al., 2014). Other groups have also associated patients with severe cirrhosis and hepatic encephalopathy with overgrowth of Enterobacteriaceae bacteria (Chen et al., 2011).

\section{ROLE OF GUT MICROBIOTA IN HEPATIC VIRAL INFECTIONS}

Acute viral hepatitis due to hepatitis $\mathrm{A}$ and $\mathrm{E}$ viral infections is a major community health problem especially in developing countries. Hepatitis A and E cause acute infection which could be short-lived and self-clearing unless the subjects are immunocompromised or in transplant settings. Acute hepatitis E infection also becomes detrimental and life-threatening during pregnancy, affecting both the mother and the child.

Both hepatitis A and E are RNA viruses that transmit through oral fecal routes (Lemon et al., 2018) and may have devastating effects on intestinal microflora. It was observed that administration of the healthy probiotic bacterium like Enterococcus faecium NCIMB 10415 affects the reduction as well as the removal of enteric HEV viruses in pigs (Kreuzer et al., 2012). However, there is lack of relevant data in humans.

As per the World Health Organization (WHO), hepatitis $\mathrm{B}$ virus (HBV) infection caused 887,000 deaths in 2015 and 4.5 million (16.7\%) diagnosed with chronic infection in 2016. Similarly, hepatitis C virus (HCV) caused 399,000 deaths with an estimated 71 million diagnosed with chronic infection in 2016. Both these viruses cause chronic infections at $10 \%$ in $\mathrm{HBV}$ and more than $30 \%$ in HCV leading to cirrhosis and hepatocellular carcinoma. Hepatic viruses have evolved mechanisms to avoid their detection from the host innate and adaptive immunity 


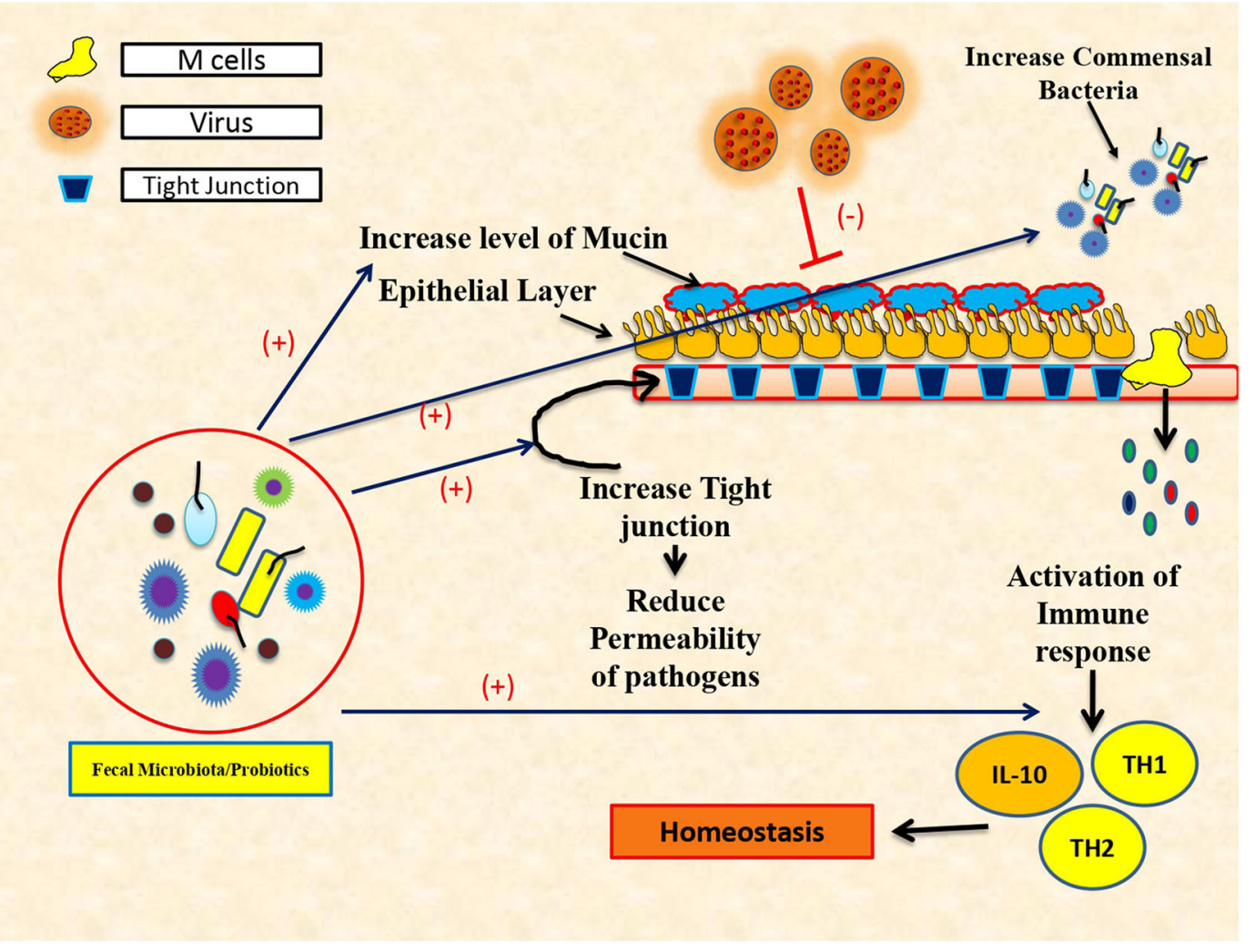

FIGURE 1 | Protective role of fecal microbiota transplantation and use of probiotics in immune restoration.

and characterized as viral escape (Visvanathan et al., 2007). It is observed that chronic hepatitis patients have larger translocation of the intestinal microbiota (Lu et al., 2011; Li et al., 2018).

Bacterial translocation cause intestinal inflammation via dysregulation of immune cell, overgrowth of pathogenic bacteria, as well as dysfunction of the primary barrier (Hill et al., 2010). $\mathrm{Xu}$ et al. (2015) also supported the fact that intestinal flora loses homeostasis during dysbiosis, which in fact helps the advancement of hepatitis viral infection (Xu et al., 2015).

Therefore, it is now understood that during chronicity, commensal microbiota have greater impact not only on viral host cell interaction but also on viral replication.

In viral hepatitis, few harmful bacteria like Escherichia coli, Enterobacteriaceae, Enterococcus faecalis, and Faecalibacterium prausnitzii directly alter the profile of good intestinal microbiota with a lower number of intestinal lactic acid species such as Lactobacillus, Pediococcus, Weissella, and Leuconostoc (Bajaj et al., 2014; Chen et al., 2016). Some of the bacterial species, i.e., Neisseria, E. coli, Enterobacteriaceae, E. faecalis, F. prausnitzii, and Gemella, are also found responsible for the progression of hepatitis $\mathrm{B}$ and $\mathrm{C}$ virus-related cirrhosis and primary biliary cirrhosis (Chen et al., 2016; Mohamadkhani, 2018). Candida is also frequently found in patients with hepatitis B-related cirrhosis (Cui et al., 2013).

\section{Role of Gut Microbiota in Hepatitis B Viral Infection}

Dysbiosis of gut microbiota in chronic hepatitis B infection affects disease pathogenesis and causes liver failure in a large proportion. LPS (lipopolysaccharides) from the outer membrane of gram-negative bacteria help in the activation of innate immune response by recognizing TLRs, especially TLR2 and 4. HBV infection leads to progressive decline in butyrate-producing bacteria. However, LPS-producing genera is enriched in $\mathrm{HBV}$ infection. In $\mathrm{HBV}$ infection, a beneficial bacterium, Lachnospiraceae, plays a role in the management of HBV infection via reduction in LPS section and bacterial translocation (Chen et al., 2011; Ren et al., 2019). Studies have shown the role of Faecalibacterium, Pseudobutyrivibrio, Lachnoclostridium, Ruminoclostridium, Prevotella, Alloprevotella, and Phascolarctobacterium in potential anti-inflammatory SCFA activity, which increases the abundance of butyrate compared to normal subjects (Liu et al., 2019). Lu et al. (2011) have demonstrated that copy numbers of $F$. prausnitzii, E. faecalis, Enterobacteriaceae, Bifidobacteria, and lactic acid bacteria (Lactobacillus, Pediococcus, Leuconostoc, and Weissella) have marked variation in the intestine of $\mathrm{HBV}$ cirrhotic patients. During HBV infection, dysbiosis in the oral microbiota was observed, and yellow tongue coating is suggestive of a reduction in Bacteroidetes but an increase 
in Proteobacteria. Zhao et al. (2018) also suggested positive correlation of Neisseriaceae with the serum HBV-DNA.

Cirrhotic patients with HBV infection showed a significant decrease in the Bifidobacteriaceae/Enterobacteriaceae (B/E) ratio (Lu et al., 2011), while Yun et al. observed no difference in the $\mathrm{B} / \mathrm{E}$ ratio in HBsAg + with normal or high ALT and in noncirrhotic HBV carriers (Yun et al., 2019). It means the B/E ratio is disturbed only in cirrhosis. However, other study observed that the Megasphaera genus from the Firmicutes phylum was abundant in the HBsAg+ high ALT group than the normal ALT. In patients with normal ALT, butyrate-producing bacteria like Anaerostipes are more in feces compared to HBsAg-ve (Yun et al., 2019). It is interesting to note that both Megasphaera and Anaerostipes produce SCFA as a by-product of lactate fermentation and butyrate. However, butyrate is known as anticarcinogenic and anti-inflammatory, and plays a role in oxidative stress (Hamer et al., 2008). Another study suggests that chronic hepatitis B infected cirrhotic patients exhibit a decrease in Bifidobacteria and Lactobacillus levels, while significantly increasing Enterococcus and Enterobacteriaceae levels compared to healthy individuals.

Bacterial translocation is also observed in the development of hepatocellular carcinoma (HCC). Recently, Wang et al. have defined the serum zonulin as an intestinal permeability marker and showed its association with AFP levels in HBV-associated liver cirrhosis and HCC. They are helpful in correlating it with advanced stages of the diseases (Fasano, 2012).

The use of probiotic in HBV-infected patients showed benefit and suggested that probiotic VSL\#3 plays an important role in the management of HBV viral infection (Dhiman et al., 2014).

\section{Role of Gut Microbiota in Hepatitis C Viral Infection}

Chronic hepatitis C infection is another leading cause of cirrhosis, HCC, and in some cases, liver failure and death. In majority, Enterobacteriaceae and Bacterioidetes increased in chronic HCV patients, but Firmicutes found to be decreased. HCV infection cause marked elevation in LPS, which is suggestive of microbial translocation and inflammation during disease progression (Dolganiuc et al., 2007; Inoue et al., 2018). On the other hand, it was observed that antiviral treatment of HCV with ribavirin (RBV) and immune modulator pegylated interferon (PEG-IFN) has no direct impact on gut dysbiosis. In fact, it increases the production of bile acids, which is important for gut microbiota (Ponziani et al., 2018). Some pathogenic bacteria such as Enterobacteriaceae, Staphylococcus, and Enterococcus decreased the bile acid in HCV-infected cirrhotic patients, which normalized after a direct-acting antiviral treatment. Oral direct-acting antivirals (DAAs) were also found to be helpful in improving gut especially Lachnospira and Dorea genera, and restored TNFa levels (Pérez-Matute et al., 2019,?).

But after DAA treatment, expression of calprotectin, ZO1, and LPS was found more in HCV patients with cirrhosis. It was also suggested that during HCV infection, L. acidophilus and Bifidobacterium spp. can act as a supportive supplement with antiviral and antibacterial activities (Dore et al., 2014).
Immune response in $\mathrm{HCV}$ patients can be stimulated by useful microbiota via activation of $\mathrm{CD} 3+$ cells and $\mathrm{CD} 56+\mathrm{NK}$ cell counts, which were explained by Doskali et al. (2011) and further suggested that good flora increases the cytotoxic effects of NK cells against viral infected cells inhibiting the replication of HCV. Use of probiotics in $\mathrm{HCV}$-infected patients with cirrhosis was significantly beneficial (Preveden et al., 2017).

Another hepatic virus, hepatitis D virus, is a new player and not much is known about it yet. It was also suggested that endotoxemia in HCV and HDV patients seems to be multifactorial, likely depending on impaired phagocytic functions and reduced T-cell-mediated antibacterial activity (Kefalakes and Rehermann, 2019).

\section{MICROBIOTA MODULATES MOLECULAR SIGNALING IN HEPATITIS}

LPS is the key component of gram-negative bacteria, i.e., Enterobacteriaceae. The active receptor for LPS is CD14/TLR4/MD2 receptor complex on induction, which secretes many pro-inflammatory cytokines including tumor necrosis factor- $\alpha$, IL-1, IL- 6 , and chemokines through the NF- $\kappa$ B signaling (Fooladi et al., 2010; Seki and Schnabl, 2012; Bryant et al., 2015) to cause liver injury. In the intestinal tract, LPS downregulates the expression of various tight junction proteins (ZO-1 and closed protein) by increasing the permeability of the intestinal mucosa and enters the blood flow through the portal venous system (Park et al., 2010). In liver, Kupffer cells as specialized macrophages are induced by the LPS-TLR4 pathway for the release of immunosuppressive mediators, such as IL-10, which in turn suppress the release of inflammatory mediators by Kupffer cells (Dixon et al., 2013). In this way, during viral hepatitis, virus specific immune responses are suppressed and ultimately inhibit efficient clearing of bacteria as well as viruses.

In addition to LPS, unmethylated CpG DNA, bacterial DNA/RNA bacterial cell wall also contains teichoic acid, peptidoglycan, and specialized proteins (flagellin). Bacterial DNA/RNA is recognized by TLRs as well as all components of cell-wall-like teichoic acid and peptidoglycan also recognized by TLR2, while TLR5 got activated by flagellin. dsRNA bacteria are recognized by TLR3. ssRNA activates receptors of both TLR7 and TLR8. All these TLRs ultimately stimulate the JAKSTAT pathway. Hepatitis viruses are also recognized by TLRs in the liver or in the intestine and activate downstream signaling pathways (Mencin et al., 2009).

Unmethylated CpG DNAs are found abundantly in the Lactobacillus family, i.e., L. casei, L. plantarum, L. rhamnosus, and others like Bifidobacteria, Proteobacteria, and Bacteroidetes in the intestinal flora of animals. Unmethylated CpG DNA is sensed by TLR9, expressed on various mononuclear cells, and stimulates both innate immune response as well as adaptive immune response (Krieg, 2006; Kauppila et al., 2013). Activation the of CpG-TLR9 pathway stimulates downstream molecules of MyD88 such as IRAK4, TRAF6, and IRAK1, ultimately triggering NF$\kappa \mathrm{B}$ and MAPK signaling pathways. These downstream pathways help in the activation of DCs for the secretion of cytokines and 
TABLE 1 | Randomized FMT clinical trials for the treatment of chronic hepatitis B infection.

\begin{tabular}{|c|c|c|c|c|c|c|c|c|c|}
\hline S.No & Study title & Study type & $\begin{array}{c}\text { No. of } \\
\text { subjects }\end{array}$ & $\begin{array}{l}\text { Intervention/ } \\
\text { Treatment }\end{array}$ & Status & Phase & $\begin{array}{l}\text { Primary outcome } \\
\text { measures }\end{array}$ & Secondary outcome measures & $\begin{array}{l}\text { ClinicalTrials.gov } \\
\text { Identifier: }\end{array}$ \\
\hline 1. & $\begin{array}{l}\text { Randomized Controlled Trial } \\
\text { Comparing the Efficacy and } \\
\text { Safety of FMT in Hepatitis B } \\
\text { Reactivation Leads to Acute } \\
\text { on Chronic Liver Failure. } \\
\text { Location: } \\
\text { Institute of liver and Biliary } \\
\text { Sciences } \\
\text { New Delhi, Delhi, India }\end{array}$ & $\begin{array}{l}\text { Interventional } \\
\text { (Clinical Trial) }\end{array}$ & 64 & $\begin{array}{l}\text { Drug: Tenofovir } \\
\text { Drug: Fecal Microbiota } \\
\text { Transplantation (FMT) }\end{array}$ & Completed & Completed & $\begin{array}{l}\text { Transplant free survival. } \\
\text { [Time Frame: } 3 \text { months] }\end{array}$ & $\begin{array}{l}\text { Reduction in Hepatitis B Virus DNA } \\
\text { level } \geq 2 \text { log. [Time Frame: } 2 \\
\text { weeks] } \\
\text { Improvement in MELD (Model for } \\
\text { End Stage Liver Disease) score. } \\
\text { [Time Frame: } 2 \text { weeks] }\end{array}$ & NCT02689245 \\
\hline 2. & $\begin{array}{l}\text { Study on Effect of Intestinal } \\
\text { Microbiota Transplantation } \\
\text { in Chronic Hepatitis B } \\
\text { Location: Zhongshan } \\
\text { Hospital Affiliated to Xiamen } \\
\text { University } \\
\text { Xiamen, Fujian, China }\end{array}$ & $\begin{array}{l}\text { Interventional } \\
\text { (Clinical Trial) }\end{array}$ & 60 & $\begin{array}{l}\text { Other: intestinal } \\
\text { microbiota transplant } \\
\text { Drug: Antiviral Agents }\end{array}$ & Recruiting & N.A. & $\begin{array}{l}\text { Change of serum hepatitis B } \\
\text { virus e antigen( } \mathrm{HBeAg} \text { level } \\
\text { [Time Frame: } 1,3,6 \\
\text { months] } \\
\text { Serum hepatitis B virus e } \\
\text { antigen(HBeAg) levels is } \\
\text { measured in } \mathrm{S} / \mathrm{CO}\end{array}$ & $\begin{array}{l}\text { Change of serum hepatitis B virus } \\
\text { surface antigen(HBsAg) level [Time } \\
\text { Frame: } 1,3,6 \text { months] Serum } \\
\text { hepatitis B virus surface } \\
\text { antigen(HBsAg) levels is measured } \\
\text { in IU/mL. } \\
\text { Change of serum anti-hepatitis B } \\
\text { virus e antigen(anti-HBe) [Time } \\
\text { Frame: } 1,3,6 \text { months] Appearance } \\
\text { of serum anti-hepatitis B virus e } \\
\text { antigen(anti-HBe) suggest the ability } \\
\text { of body to resistant HBV. } \\
\text { Change of serum anti-hepatitis B } \\
\text { virus surface antigen(anti-HBs) } \\
\text { [Time Frame: } 1,3,6 \text { months] } \\
\text { Appearance of serum anti-hepatitis } \\
\text { B virus surface antigen(anti-HBs) } \\
\text { suggest the ability of body to } \\
\text { resistant HBV. } \\
\text { Changes of gut microbiota [Time } \\
\text { Frame: } 1,3,6 \text { months] Alpha and } \\
\text { Beta diversity of Gl microbiota by } \\
\text { High-throughput sequencing (16S } \\
\text { rRNA) on baseline line and } 1,3,6 \\
\text { months after treatment } \\
\text { Relief of constipation [Time Frame: } \\
1,3,6 \text { months]; Relief of diarrhea } \\
\text { [Time Frame: } 1,3,6 \text { months]; Relief } \\
\text { of abdominal pain [Time Frame: } 1 \text {, } \\
3,6 \text { months] The onset and } \\
\text { duration of constipation will be } \\
\text { assessed by "Evaluation Score } \\
\text { Table of Gastrointestinal } \\
\text { Symptoms." }\end{array}$ & NCT03429439 \\
\hline
\end{tabular}


chemokines (Krieg, 2006; Kauppila et al., 2013). Chronic HBV patients have reduced Lactobacillus and Bifidobacteria. Both are rich in unmethylated CpG DNA levels, ultimately affecting the CPG DNA-TLR9 pathway and immune response on HBV (Lin and Zhang, 2017).

\section{ROLE OF FECAL MICROBIAL TRANSPLANTATION (FMT) IN VIRAL HEPATITIS}

FMT mainly involves the insertion of healthy microbiota in the diseased gut. In brief, fecal matter derived from a healthy family member of the patient receiving the same diet as the patient is processed and introduced in the intestinal tract of the patient. These have minimal side effects and proved helpful in reinstating healthy gut flora in the patient. FMT administration can be done using several routes such as oral, nasogastric, nasoduodenal, nasojejunal, endoscopic, rectal, and colonoscopic or midgut transendoscopic enteral tubing (Cui et al., 2015; Tang et al., 2017). For cirrhotic patients with dysbiosis, small bowel route is most affected, while mostly used route is oral delivery. In severe alcoholic hepatitis (SAH), in comparison to steroids, FMT is associated with decreased disease severity and improved survival. Earlier, Wang et al. (2017b) have observed that FMT restored the cognitive function, liver function indexes, and TLR response in carbon tetrachloride $\left(\mathrm{CCl}_{4}\right)$-induced acute hepatitis in rats.

Woodhouse et al. have observed in a PROFIT clinical trial the benefits of fecal microbiota transplantation in the small bowel of cirrhotic patients (Woodhouse et al., 2019). Meiglani et al. (2020) also observed that cirrhotic patients with antibioticresistant Clostridioides difficile infection (CDI) responded well after FMT treatment. In fact, fecal microbiota of alcoholresistant mice when given to alcohol-sensitive mice has reduced Bacteroidetes and increased Actinobacteria as well as Firmicutes and protected steatosis development (Ferrere et al., 2017). Limited studies are published yet on FMT administration in alcohol-related liver disease. However, all these studies showed immense benefit of FMT. Bajaj et al. (2017) observed the recovery of cognitive function and hepatic encephalopathy in patients under clinical trial after administration of FMT. Studies recently published from our center have found better efficiency of FMT

\section{REFERENCES}

Bajaj, J. S., Heuman, D. M., Hylemon, P. B., Sanyal, A. J., White, M. B., Monteith, P., et al. (2014). The cirrhosis dysbiosis ratio defines changes in the gut microbiome associated with cirrhosis and its complications. J. Hepatol. 60, 940-947. doi: 10.1016/j.jhep.2013. 12.019

Bajaj, J. S., Kassam, Z., Fagan, A., Gavis, E. A., Liu, E., Cox, I. J., et al. (2017). Fecal microbiota transplant from a rational stool donor improves hepatic encephalopathy: a randomized clinical trial. Hepatology 66, 1727-1738. doi: 10.1002/hep.29306

Bryant, C. E., Symmons, M., and Gay, N. J. (2015). Toll-like receptor signalling through macromolecular protein complexes. Mol. Immunol. 63, 162-165. doi: 10.1016/j.molimm.2014.06.033 in severe alcoholic patients than standard medical treatment (Sarin et al., 2019). There are only a couple of randomized FMT clinical trials for chronic hepatitis B infected patients (Table 1).

Recently, groups have addressed how FMT is modulating immunity in gut and liver. Mucosa-associated invariant $\mathrm{T}$ (MAIT) cells are found abundant in liver $(20 \%$ to $50 \%$ of intrahepatic T cells), gut, peripheral blood, as well as lungs. Gao et al. have observed that functional MAIT cells were altered in $\mathrm{SAH}$ resulting in more bacterial infection in patients. Alteration in circulating MAIT cells is observed with defective antibacterial cytokine/cytotoxic response against the infection (Gao et al., 2018). They believe that FMT administration has a profound effect on the expression of MAIT cells in alcohol-related diseases.

\section{SUMMARY AND CONCLUSION}

Gut microbiota has an important role in viral, alcoholic, and metabolic liver diseases. Gut microbiota plays a crucial role in modulating the toll-like receptors, NF- $\mathrm{B}$ signaling, janus kinase/signal transducer and transcription (JAK/STAT) pathway, and $\mathrm{CD} 4+\mathrm{T}$ cell activation. Numerous useful microbiotas like Ruminoclostridium, Faecalibacterium, Lachnoclostridium, Prevotella, Alloprevotella, Pseudobutyrivibrio, and Phascolarctobacterium play an important role in potentiating anti-inflammatory short chain fatty acid (SCFA) activity and increased the butyrate abundance, which play a crucial role in the management of various hepatitis-related viral infections. Fecal microbiota transplantation became an attractive and safest mode of treatment for the management of various liver diseases especially in severe alcoholic hepatitis. Despite recent publications, there are still gaps in understanding the role of microbiota in viral hepatitis especially in acute HAV and HEV viral infections. Therefore, there is a need to explore more in these infections.

\section{AUTHOR CONTRIBUTIONS}

RS and OB written the review article. NT provide valuable suggestions, corrected, and revised. All authors contributed to the article and approved the submitted version.
Canny, G. O., and McCormick, B. A. (2008). Bacteria in the intestine, helpful residents or enemies from within? Infection and immunity. Am. Soc. Microbiol. 76, 3360-3373. doi: 10.1128/IAI.00187-08

Chen, Y., Ji, F., Guo, J., Shi, D., Fang, D., and Li, L. (2016). Dysbiosis of small intestinal microbiota in liver cirrhosis and its association with etiology. Sci. Rep. 6:34055. doi: 10.1038/srep34055

Chen, Y., Yang, F., Lu, H., Wang, B., Chen, Y., Lei, D., et al. (2011). Characterization of fecal microbial communities in patients with liver cirrhosis. Hepatology 54, 562-572. doi: 10.1002/hep.24423

Cremer, J., Arnoldini, M., and Hwa, T. (2017). Effect of water flow and chemical environment on microbiota growth and composition in the human colon. Proc. Natl. Acad. Sci. U.S.A. 114, 6438-6443. doi: 10.1073/pnas.1619598114

Cui, B., Feng, Q., Wang, H., Wang, M., Peng, Z., Li, P., et al. (2015). Fecal microbiota transplantation through mid-gut for refractory $\mathrm{C}$ rohn's disease: 
safety, feasibility, and efficacy trial results. J. Gastroenterol. Hepatol. 30, 51-58. doi: 10.1111/jgh.12727

Cui, L., Morris, A., and Ghedin, E. (2013). The human mycobiome in health and disease. Genome Med. 5:63. doi: 10.1186/gm467

Dhiman, R. K., Rana, B., Agrawal, S., Garg, A., Chopra, M., Thumburu, K. K., et al. (2014). Probiotic VSL $\ 3$ reduces liver disease severity and hospitalization in patients with cirrhosis: a randomized, controlled trial. Gastroenterology 147, 1327-1337. doi: 10.1053/j.gastro.2014.08.031

Dixon, L. J., Barnes, M., Tang, H., Pritchard, M. T., and Nagy, L. E. (2013). Kupffer cells in the liver. Compr. Physiol. 3, 785-797. doi: 10.1002/cphy.c120026

Dolganiuc, A., Norkina, O., Kodys, K., Catalano, D., Bakis, G., Marshall, C., et al. (2007). Viral and host factors induce macrophage activation and loss of toll-like receptor tolerance in chronic HCV infection. Gastroenterology 133, 1627-1636. doi: 10.1053/j.gastro.2007.08.003

Dore, G., Ward, J., and Thursz, M. (2014). Hepatitis C disease burden and strategies to manage the burden (Guest Editors Mark Thursz, Gregory Dore and John Ward). J. Viral. Hepat. 21(Suppl. 1), 1-4. doi: 10.1111/jvh.12253

Doskali, M., Tanaka, Y., Ohira, M., Ishiyama, K., Tashiro, H., Chayama, K., et al. (2011). Possibility of adoptive immunotherapy with peripheral bloodderived $\mathrm{CD}^{-} \mathrm{CD}^{-} 6^{+}$and $\mathrm{CD}^{+}{ }^{+} \mathrm{CD} 56^{+}$cells for inducing anti-hepatocellular carcinoma and anti-hepatitis C virus activity. J. Immunother. 34, 129-138. doi: 10.1097/CJI.0b013e3182048c4e

Fasano, A. (2012). Intestinal permeability and its regulation by zonulin: diagnostic and therapeutic implications. Clin. Gastroenterol. Hepatol. 10, 1096-1100. doi: 10.1016/j.cgh.2012.08.012

Fernández, M. F., Reina-Pérez, I., Astorga, J. M., Rodriguez-Carrillo, A., Plaza-Diaz, J., and Fontana, L. (2018). Breast cancer and its relationship with the microbiota. Int. J. Environ. Res. Public Health 15:1747. doi: 10.3390/ijerph15081747

Ferrere, G., Wrzosek, L., Cailleux, F., Turpin, W., Puchois, V., Spatz, M., et al. (2017). Fecal microbiota manipulation prevents dysbiosis and alcoholinduced liver injury in mice. J. Hepatol. 66, 806-815. doi: 10.1016/j.jhep.2016. 11.008

Fooladi, A. I., Tavakoli, H., and Naderi, A. (2010). Detection of enterotoxigenic Staphylococcus aureus isolates in domestic dairy products. Iran. J. Microbiol. 2:137.

Gao, B., Ma, J., and Xiang, X. (2018). MAIT cells: a novel therapeutic target for alcoholic liver disease? Gut 67, 784-786. doi: 10.1136/gutjnl-2017-315284

Hamer, H. M., Jonkers, D., Venema, K., Vanhoutvin, S., Troost, F., and Brummer, R. J. (2008). The role of butyrate on colonic function. Aliment. Pharmacol. Ther. 27, 104-119. doi: 10.1111/j.1365-2036.2007.03562.x

Hill, D. A., Hoffmann, C., Abt, M. C., Du, Y., Kobuley, D., Kirn, T. J., et al. (2010). Metagenomic analyses reveal antibiotic-induced temporal and spatial changes in intestinal microbiota with associated alterations in immune cell homeostasis. Mucosal. Immunol. 3, 148-158. doi: 10.1038/mi.2009.132

Hooper, L. V., Xu, J., Falk, P. G., Midtvedt, T., and Gordon, J. I. (1999). A molecular sensor that allows a gut commensal to control its nutrient foundation in a competitive ecosystem. Proc. Natl. Acad. Sci. U.S.A. 96, 9833-9838. doi: 10.1073/pnas.96.17.9833

Ichinohe, T., Pang, I. K., Kumamoto, Y., Peaper, D. R., Ho, J. H., Murray, T. S., et al. (2011). Microbiota regulates immune defense against respiratory tract influenza a virus infection. Proc. Natl. Acad. Sci. U.S.A. 108, 5354-5359. doi: $10.1073 /$ pnas. 1019378108

Inoue, T., Nakayama, J., Moriya, K., Kawaratani, H., Momoda, R., Ito, K., et al. (2018). Gut dysbiosis associated with hepatitis C virus infection. Clin. Infect. Dis. 67, 869-877. doi: 10.1093/cid/ciy205

Jiminez, J. A., Uwiera, T. C., Abbott, D. W., Uwiera, R. R., and Inglis, G. D. (2016). Impacts of resistant starch and wheat bran consumption on enteric inflammation in relation to colonic bacterial community structures and short-chain fatty acid concentrations in mice. Gut Pathog. 8:67. doi: 10.1186/s13099-016-0149-6

Karst, S. M. (2016). The influence of commensal bacteria on infection with enteric viruses. Nat. Rev. Microbiol. 14:197. doi: 10.1038/nrmicro.2015.25

Kauppila, J. H., Karttunen, T. J., Saarnio, J., Nyberg, P., Salo, T., Graves, D. E., et al. (2013). Short DNA sequences and bacterial DNA induce esophageal, gastric, and colorectal cancer cell invasion. APMIS 121, 511-522. doi: 10.1111/apm.12016
Kefalakes, H., and Rehermann, B. (2019). Inflammation drives an altered phenotype of mucosal-associated invariant T cells in chronic hepatitis D virus infection. J. Hepatol. 71, 237-239. doi: 10.1016/j.jhep.2019.05.024

Khanna, S., and Tosh, P. K. (2014). A clinician's primer on the role of the microbiome in human health and disease. Mayo Clin. Proc. 89, 107-114. doi: 10.1016/j.mayocp.2013.10.011

Kreuzer, S., Machnowska, P., Aßmus, J., Sieber, M., Pieper, R., Schmidt, M. F., et al. (2012). Feeding of the probiotic bacterium Enterococcus faecium NCIMB 10415 differentially affects shedding of enteric viruses in pigs. Vet. Res. 43:58. doi: 10.1186/1297-9716-43-58

Krieg, A. M. (2006). Therapeutic potential of Toll-like receptor 9 activation. Nat. Rev. Drug Discov. 5, 471-484. doi: 10.1038/nrd2059

Lee, H., and Ko, G. (2016). Antiviral effect of vitamin A on norovirus infection via modulation of the gut microbiome. Sci. Rep. 6:25835. doi: 10.1038/srep25835

Lemon, S. M., Ott, J. J., van Damme, P., and Shouval, D. (2018). Type A viral hepatitis: a summary and update on the molecular virology, epidemiology, pathogenesis and prevention. J. Hepatol. 68, 167-184. doi: 10.1016/j.jhep.2017.08.034

Li, D., Yan, P., Abou-Samra, A. B., Chung, R., and Butt, A. (2018). Proton pump inhibitors are associated with accelerated development of cirrhosis, hepatic decompensation and hepatocellular carcinoma in noncirrhotic patients with chronic hepatitis C infection: results from ERCHIVES. Aliment. Pharmacol. Ther. 47, 246-258. doi: 10.1111/apt.14391

Li, H., Gao, Z., Zhang, J., Ye, X., Xu, A., Ye, J., et al. (2012). Sodium butyrate stimulates expression of fibroblast growth factor 21 in liver by inhibition of histone deacetylase 3. Diabetes 61, 797-806. doi: 10.2337/db11-0846

Lin, L., and Zhang, J. (2017). Role of intestinal microbiota and metabolites on gut homeostasis and human diseases. BMC Immunol. 18:12. doi: 10.1186/s12865-016-0187-3

Liu, Q., Li, F., Zhuang, Y., Xu, J., Wang, J., Mao, X., et al. (2019). Alteration in gut microbiota associated with hepatitis $B$ and non-hepatitis virus related hepatocellular carcinoma. Gut Pathog. 11:11. doi: 10.1186/s13099-018-0281-6

Lu, H., Wu, Z., Xu, W., Yang, J., Chen, Y., and Li, L. (2011). Intestinal microbiota was assessed in cirrhotic patients with hepatitis B virus infection. Microb. Ecol. 61, 693-703. doi: 10.1007/s00248-010-9801-8

Meiglani, A., Alimirah, M., Ramesh, M., and Salgia, R. (2020). Fecal microbiota transplantation for Clostriodioides difficile infection in patients with chronic liver disease. Int. J. Hepatol. 2020:1874570. doi: 10.1155/2020/1874570

Mencin, A., Kluwe, J., and Schwabe, R. F. (2009). Toll-like receptors as targets in chronic liver diseases. Gut 58, 704-720. doi: 10.1136/gut.2008.156307

Minemura, M., and Shimizu, Y. (2015). Gut microbiota and liver diseases. World J. Gastroenterol. 21:1691. doi: 10.3748/wjg.v21.i6.1691

Mohamadkhani, A. (2018). On the potential role of intestinal microbial community in hepatocarcinogenesis in chronic hepatitis B. Cancer Med. 7, 3095-3100. doi: 10.1002/cam4.1550

Moratalla, A., Gómez-Hurtado, I., Santacruz, A., Moya, Á., Peiró, G., Zapater, P., et al. (2014). Protective effect of Bifidobacterium pseudocatenulatum CECT 7765 against induced bacterial antigen translocation in experimental cirrhosis. Liver Int. 34, 850-8. doi: 10.1111/liv.12380

O'Hara, A. M., and Shanahan, F. (2007). Gut microbiota: mining for therapeutic potential. Clin. Gastroenterol. Hepatol. 5, 274-284. doi: 10.1016/j.cgh.2006.12.009

Park, E. J., Thomson, A. B., and Clandinin, M. T. (2010). Protection of intestinal occludin tight junction protein by dietary gangliosides in lipopolysaccharideinduced acute inflammation. J. Pediatr. Gastroenterol. Nutr. 50, 321-328. doi: 10.1097/MPG.0b013e3181ae2ba0

Pérez-Matute, P., Íñiguez, M., Villanueva-Millán, M. J., Recio-Fernández, E., and Vázquez, A. M., Sánchez, S. C., et al. (2019). Short-term effects of direct-acting antiviral agents on inflammation and gut microbiota in hepatitis C-infected patients. Eur. J. Inter. Med. 67, 47-58. doi: 10.1016/j.ejim.2019.06.005

Ponziani, F. R., Putignani, L., Paroni Sterbini, F., Petito, V., Picca, A., Del Chierico, F., et al. (2018). Influence of hepatitis C virus eradication with direct-acting antivirals on the gut microbiota in patients with cirrhosis. Aliment. Pharmacol. Ther. 48, 1301-1311. doi: 10.1111/apt.15004

Preveden, T., Scarpellini, E., Milić N., Luzza, F., and Abenavoli, L. (2017). Gut microbiota changes and chronic hepatitis C virus infection. Expert Rev. Gastroenterol. Hepatol. 11, 813-819. doi: 10.1080/17474124.2017.1343663 
Raimondi, S., Amaretti, A., Gozzoli, C., Simone, M., Righini, L., Candeliere, F., et al. (2019). Longitudinal survey of fungi in the human gut: ITS profiling, phenotyping and colonization. Front. Microbiol. 10:1575. doi: $10.3389 /$ fmicb. 2019.01575

Ren, Z., Li, A., Jiang, J., Zhou, L., Yu, Z., Lu, H., et al. (2019). Gut microbiome analysis as a tool towards targeted non-invasive biomarkers for early hepatocellular carcinoma. Gut 68, 1014-1023. doi: 10.1136/gutjnl-2017-315084

Rigo-Adrover M del, M., Van Limpt, K., Knipping, K., Garssen, J., Knol, J., Costabile, A., et al. (2018). Preventive effect of a synbiotic combination of galacto-and fructooligosaccharides mixture with Bifidobacterium breve M$16 \mathrm{~V}$ in a model of multiple rotavirus infections. Front. Immunol. 9:1318. doi: 10.3389/fimmu.2018.01318

Sanduzzi Zamparelli, M., Rocco, A., Compare, D., and Nardone, G. (2017). The gut microbiota: A new potential driving force in liver cirrhosis and hepatocellular carcinoma. United Eur. Gastroenterol. J. 5, 944-953. doi: $10.1177 / 2050640617705576$

Sarin, S. K., Pande, A., and Schnabl, B. (2019). Microbiome as a therapeutic target in alcohol-related liver disease. J. Hepatol. 70, 260-272. doi: 10.1016/j.jhep.2018.10.019

Seki, E., and Schnabl, B. (2012). Role of innate immunity and the microbiota in liver fibrosis: crosstalk between the liver and gut. J. Physiol. 590, 447-458. doi: 10.1113/jphysiol.2011.219691

Tang, G., Yin, W., and Liu, W. (2017). Is frozen fecal microbiota transplantation as effective as fresh fecal microbiota transplantation in patients with recurrent or refractory Clostridium difficile infection: a meta-analysis? Diagn. Microbiol. Infect. Dis. 88, 322-329. doi: 10.1016/j.diagmicrobio.2017.05.007

Venegas, D. P., Marjorie, K., Landskron, G., González, M. J., Quera, R., Dijkstra, G., et al. (2019). Short chain fatty acids (SCFAs)-mediated gut epithelial and immune regulation and its relevance for inflammatory bowel diseases. Front. Immunol. 10:277. doi: 10.3389/fimmu.2019.00277

Visvanathan, K., Skinner, N. A., Thompson, A. J., Riordan, S. M., Sozzi, V., Edwards, R., et al. (2007). Regulation of Toll-like receptor-2 expression in chronic hepatitis B by the precore protein. Hepatology 45, 102-110. doi: 10.1002/hep.21482

Wang, J., Wang, Y., Zhang, X., Liu, J., Zhang, Q., Zhao, Y., et al. (2017a). Gut microbial dysbiosis is associated with altered hepatic functions and serum metabolites in chronic hepatitis B patients. Front. Microbiol. 8:2222. doi: 10.3389/fmicb.2017.02222

Wang, W.-W., Zhang, Y., Huang, X.-B., You, N., Zheng, L., and Li, J. (2017b). Fecal microbiota transplantation prevents hepatic encephalopathy in rats with carbon tetrachloride-induced acute hepatic dysfunction. World J. Gastroenterol. 23:6983. doi: 10.3748/wjg.v23.i38.6983

Woodhouse, C. A., Patel, V. C., Goldenberg, S., Sanchez-Fueyo, A., China L., O'Brien, A., et al. (2019). PROFIT, a prospective, randomised placebo controlled feasibility trial of faecal microbiota transplantation in cirrhosis: study protocol for a single-blinded trial. BMJ Open 9:e023518. doi: 10.1136/bmjopen-2018-023518

$\mathrm{Xu}, \mathrm{D}$., Huang, Y., and Wang, J. (2015). Gut microbiota modulate the immune effect against hepatitis B virus infection. Eur. J. Clin. Microbiol. Infect. Dis. 34, 2139-2147. doi: 10.1007/s10096-015-2464-0

Yun, Y., Chang, Y., Kim, H. N., Ryu, S., Kwon, M. J., Cho, Y. K., et al. (2019). Alterations of the gut microbiome in chronic hepatitis B virus infection associated with alanine aminotransferase level. J. Clin. Med. 8:173. doi: $10.3390 /$ jcm 8020173

Zhao, Y., Mao, Y. F., Tang, Y. S., Ni, M. Z., Liu, Q. H., Wang, Y., et al. (2018). Altered oral microbiota in chronic hepatitis B patients with different tongue coatings. World J. Gastroenterol. 24:3448. doi: 10.3748/wjg.v24.i30.3448

Zheng, X., Qiu, Y., Zhong, W., Baxter, S., Su, M., Li, Q., et al. (2013). A targeted metabolomic protocol for short-chain fatty acids and branched-chain amino acids. Metabolomics 9, 818-827. doi: 10.1007/s11306-013-0500-6

Conflict of Interest: The authors declare that the research was conducted in the absence of any commercial or financial relationships that could be construed as a potential conflict of interest.

Copyright (c) 2020 Sehgal, Bedi and Trehanpati. This is an open-access article distributed under the terms of the Creative Commons Attribution License (CC BY). The use, distribution or reproduction in other forums is permitted, provided the original author(s) and the copyright owner(s) are credited and that the original publication in this journal is cited, in accordance with accepted academic practice. No use, distribution or reproduction is permitted which does not comply with these terms. 